University of South Florida

DIGITAL COMMONS

Digital Commons @ University of

@ UNIVERSITY OF SOUTH FLORIDA

South Florida

Academic Services Faculty and Staff

Publications

Tampa Library

2014

\title{
Introduction to the ISO 18626:2014 Press Release and Interview With Leif Andresen
}

LeEtta M. Schmidt

University of South Florida, Imschmidt@usf.edu

Follow this and additional works at: https://digitalcommons.usf.edu/tlas_pub

Part of the Library and Information Science Commons

\section{Scholar Commons Citation}

Schmidt, LeEtta M., "Introduction to the ISO 18626:2014 Press Release and Interview With Leif Andresen" (2014). Academic Services Faculty and Staff Publications. 179.

https://digitalcommons.usf.edu/tlas_pub/179

This Article is brought to you for free and open access by the Tampa Library at Digital Commons @ University of South Florida. It has been accepted for inclusion in Academic Services Faculty and Staff Publications by an authorized administrator of Digital Commons @ University of South Florida. For more information, please contact digitalcommons@usf.edu. 


\section{Introduction}

Like every OCLC interlibrary loan user I know, I get excited at the announcements that another country's libraries have been added to the OCLC system. I get even more excited when I hear that those libraries have joined OCLC and are lenders. Yet, I am still handling requests for items that I cannot find in OCLC. I know they exist out there somewhere in networks used by other countries, but the difficulty of finding and requesting them outside my own network is prohibitive. The answer to my problem is not how many more countries' libraries OCLC can recruit to membership; the answer is a world where my OCLC request can reach a lending library of a non-OCLC network without jumping through any extra hoops.

It sounds like a dream world where country and system boundaries need not apply. It is exactly the type of world that the new ISO Interlibrary loan transactions standard, ISO18626:2014, was written to help bring about. The International Organization for Standardization (ISO) announced the revised ISO interlibrary loan transactions standard in the accompanying July press release. This standard aims to rectify the unnecessary complexity and difficulty in implementation and testing of the old ISO interlibrary loan transaction standard, ISO 10160 and 10161.

The original ISO dealing with interlibrary loan was written in 1997, pre-dating the widespread use of an infant internet. It was based on a blind request system, or a librarian's best guess of who might own any given item. The standard relied on OSI (Open Systems Interconnection) model, which has since been replaced by TCP/IP (Transmission Protocol and Internet Protocol) as the basis for the internet (Andresen, 2011). While this language may be native to many resource sharing system developers, most interlibrary loan practitioners know only that the request management systems they use or purchase for their library should be in harmony with the suggested ISO and NISO standards. 
This harmony is all about systems communicating with each other. "Most data communications today happens by way of packets of information travelling over one or more networks. But before these networks can work together, though, they must use a common protocol, or a set of rules for transmitting and receiving these packets of data" (Frenzel, 2013). TCP/IP simplified the complex layering scheme and excessive rules of OSI and became the backbone of the internet and communication processes of many current interlibrary loan systems. Thus, the old ISO ILL standard includes data and processes that conflicted with many ILL systems, and the unnecessary complexity of ISO 10160 and 10161 may have contributed to the reason for the standard never being widely implemented (MacKeigan \& Davidson, 2012).

Yet, ISO ILL was meant to facilitate interoperability between systems like OCLC and LIBRIS (Sweden), biblioteck.dk Denmark and Gegnir in Iceland (MacKeigan \& Davidson, 2012), similar to the way NCIP enables cross-system interoperability between library circulation systems, and interlibrary loan and circulation systems (NCIP Standing Committee, 2011). A simpler standard, built to today's needs, could make system-to-system requesting easy and transparent to the system users. The new ISO ILL strives to make cross-system interlibrary loan as efficient and utilitarian as we need it to be to meet the demands of our users.

\section{Interview}

The ISO Interlibrary Loan Transactions convener, Leif Andresen of the Royal Library, Denmark was good enough to answer a few questions for us about the new ISO ILL standard.

What problems will the new standard solve for interlibrary loan?

The new standard solves the lack of an effective and easy method to transport ILL requests and messages between libraries. 
How did the editing group approach creating ISO 18626? Did they focus on the problems presented by the old standard or on new possibilities?

The background was that different groups had independently started work preparing new specifications for the exchange of ILL messages. In Denmark we focused on preparing a technical step from transport of data by Z39.50 extended service to more modern technology. The Resource Sharing Initiative had started development of specification for a successor for ISO 10160 and 10161 . These initiatives met in a discussion during the ISO SC4 (Technical Interoperability) meeting in Berlin 2012. Initially, the main focus was the problems of the old standard. The discussion continued from the SC4 meeting and a formal proposal was sent to ISO in October 2012 with some case scenarios focusing on the problems of today. Great attention was paid to defining what is needed to transport data between applications - and not to define what and how applications handle the information.

What is the reasoning behind the new standard's inclusion of 3 messages as opposed to the preceding standard's, ISO 10160 and 10161, 21 messages?

In fact the old standard's 21 messages have always been too much and too complicated. The messages after delivery are simple and have been joined to one still rather simple message. A few of the old messages were just dropped. For example, "Damage," which has always been just a "golden telefax" to say "This book is so-and-so damaged. Do you want it or shall we just throw it away," is easy to handle by fax or phone, but too complex to define in a fixed list of possibilities.

ISO 18626 drops the use of states due to the over-complication they caused the ILL workflow; can you expand on the old problem?

Use of state means, that the transaction itself is not only a message, but also a detailed specification of the internal data model in the receiving ILL application. This kind of state is virtual and 
must be reflected in all involved applications. That is the main reason to drop the use of states. Most of the implementations of states are specific for a vendor product and we only have a few examples of vendor product to vendor product interoperability. One of them is OCLC and Relais, representatives of which are my co-editors. In Denmark we have implemented most of the ILL messages, but have ignored the states and have used XML (extensible markup language). Our system runs with all vendor products on the Danish market.

Are there other notable changes outside of the reduced messages and dropping the use of states?

I would like to mention, that the editors have an interaction with the NCIP Standing Committee and have aligned both the wording of data elements and the transport mechanism with NCIP. So a notable change is also a move from technology before WWW to web service and XML.

\section{Cited}

Andresen, Leif. (2011) "ILL transactions - a next step? The Danish experience and new possibilities", Interlending \& Document Supply, Vol. 39 Iss: 4, pp.186 - 189

Frenzel, L. (2013) “What's the Difference Between the OSI Seven-Layer Network Model and TCP/IP?” Electronic Design. Oct 2, 2012. Retrieved from: http://electronicdesign.com/what-s-differencebetween/what-s-difference-between-osi-seven-layer-network-model-and-tcpip

MacKeigan, C.; Davidson, E. (2012) "The Future of ILL Interoperability." 10th Nordic Resource Sharing, Reference and Collection management Conference. Reykjavik, Oct. 5, 2012

NCIP Standing Committee (2011) Introduction to NCIP. NISO Circulation Interchange Protocol. http://www.ncip.info/introduction-to-ncip.html 